\title{
Spatial Variation of Vegetation Moisture Mapping Using Advanced Spaceborne Thermal Emission \& Reflection Radiometer (ASTER) Data
}

\author{
Vivek Kumar Singh ${ }^{1}$, Rajat Satpathy ${ }^{2}$, Reshma Parveen ${ }^{1}$, Ayyem Perumal Thillai Jeyaseelan ${ }^{1}$ \\ ${ }^{1}$ Jharkhand Space Application Center, Ranchi, Department of Information Technology, Government of Jharkhand, Ranchi, India; \\ ${ }^{2}$ Department of Remote Sensing \& GIS, Vidyasagar University, Midnapore, India. \\ Email: vivekearth@gmail.com
}

Received August 20 ${ }^{\text {th }}, 2010$; revised September 29 ${ }^{\text {th }}, 2010$; accepted October $2^{\text {nd }}, 2010$.

\begin{abstract}
Drought is a recurrent phenomenon in Jharkhand. It affects the livelihoods of the majority of its people, particularly tribals and dalits living in rural areas. Twelve of the 24 districts of the state, covering $43 \%$ of the total land area, are covered under the Drought Prone Areas Programme (DPAP). Hunger and starvation deaths are reported almost every year. Vegetation moisture content is one of the key parameters in drought monitoring, agricultural modelling and forest health mapping. In this paper the three different approaches is described using Advanced Spaceborne Thermal Emission \& Reflection Radiometer (ASTER) data for measuring the vegetation moisture content in a part of Palamu Commissionaire of Jharkhand state, which is prone to severe drought. ASTER thermal data was used to calculate land surface temperature using Normalized Differential Vegetation Index (NDVI) emissivity correction method. Reflective bands are used to determine NDVI, Modified Soil Adjustment Vegetation Index (MSAVI) \& Normalised Differential Water Index (NDWI). The three different vegetation moisture estimation methods namely MSAVI - LST (land surface temperature) feature space identification, NDWI \& Vegetation Dryness Index (VDI) is applied to determine the vegetation moisture level. The results of three methods were classified and final moisture content map was produced. The result was validated using rainfall data of study area. This study indicates that by proper pre-processing of ASTER data, it can be used to estimate the land surface temperature and vegetation moisture content and can be used for drought prediction.
\end{abstract}

Keywords: Vegetation Moisture, ASTER, LST, NDWI, VDI

\section{Introduction}

Periods of persistent abnormally dry weather known as droughts, can produce a serious agricultural, ecological and hydrological imbalance. Drought harshness depends upon the degree of moisture deficiency, duration and the size of the affected area [1]. Remote sensing is now widely used to monitor and predict vegetation characteristics for sustainable development. Imaging spectrometry has great potential for monitoring vegetation type and biophysical characteristics [2]. Vegetation reflectance spectra are often quite informative, containing information on the vegetation chlorophyll absorption bands in the visible region, the sustained high reflectance in the near infrared band, and the effects of plant water absorption in the middle infrared region.

Using that absorption and reflection characteristics of vegetation researchers have defined many vegetation indices for monitoring vegetation parameters. Normalized Differential Vegetation Index (NDVI) is used to measure the forest health. It measures the chlorophyll content within the vegetation [3]. Normalized Differential Water Index.

(NDWI) was used to measure the moisture content within the vegetation field. The surface temperature response is a function of varying vegetation cover and surface soil water content. Lambin and Ehrlich (1996) explained the Vegetation Index (VI) and Land Surface Temperature (LST) space in terms of evaporation, transpiration and fractional vegetation coverage [4]. According to Lambin and Ehrlich (1996), the variations in surface brightness temperature are highly correlated with variations in surface water content over base soil [4].

Advanced Spaceborne Thermal Emission \& Reflection Radiometer (ASTER) data have a distinct vegetation 
absorption and reflection bands. So, it is used to measure the moisture content within the vegetation field of Jharkhand state, which is regularly affected by drought. Almost every year some part of that state is affected by drought. The main objective of this study is to evaluate the potential of ASTER imagery to determine the variation of vegetation moisture within the study area. Meanwhile the area suffer drought year after year. So, for identifying the situation of drought, this study was carried out. Three approaches are used to estimate the vegetation moisture levels and then the result is compared with the rainfall status of the study area in the same time.

\section{Study Area}

The present study area is the part of Latehar, Garhwa, Palamu \& Gumla district of Jharkhand state (Figure 1). Geographically, the area is located on southern part of the Chotanagpur plateau. Maximum height of the area is about 1120 meter above mean sea level. The area drained by North Koel, Burha River and their tributaries. The area enjoys a tropical climate. The maximum temperature in summer rises to above $32^{\circ} \mathrm{C}$ and the minimum in winter falls to $03-04^{\circ} \mathrm{C}$. The average annual rainfall is about 1600 $\mathrm{mm}$. The latitudinal and longitudinal extent of the study area is as follows - Latitudinal extent $-23^{\circ} 15^{\prime} \mathrm{N}-23^{\circ} 50^{\prime} \mathrm{N}$ and Longitudinal extent $-83^{\circ} 24^{\prime} \mathrm{E}-83^{\circ} 38^{\prime} \mathrm{E}$.

\section{Methods}

\subsection{Data Used}

Advanced Spaceborne Thermal Emission and Reflection Radiometer (ASTER) Level-1A satellite data (Table 1) is used for this study. The imagery was georectified in UTM, WGS 84, and Zone-45N. Apart from satellite data ASTER DEM, SOI Toposheet on 1:50000 scale and

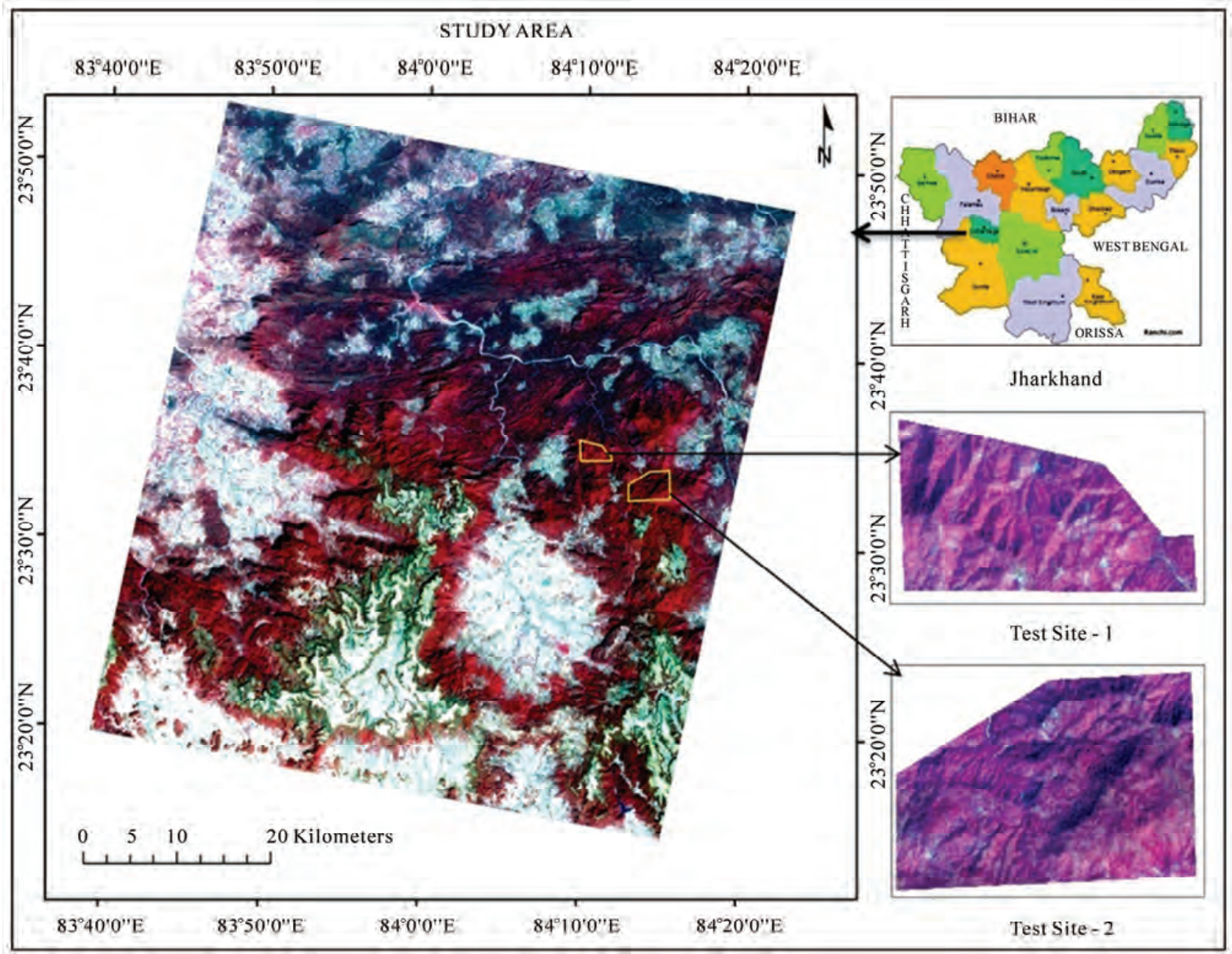

Figure 1. Location of the study area \& selected test sites. 
Table 1. ASTER satellite data specifications used for the study [5].

\begin{tabular}{|c|c|c|c|}
\hline $\begin{array}{c}\text { Data } \\
\text { Product }\end{array}$ & $\begin{array}{l}\text { Spectral } \\
\text { Bands }\end{array}$ & $\begin{array}{c}\text { Spectral range } \\
(\mu \mathrm{m})\end{array}$ & $\begin{array}{c}\text { Spatial } \\
\text { Resolution (M) }\end{array}$ \\
\hline \multirow{4}{*}{$\begin{array}{c}\text { Aster } \\
\text { L1A } \\
\text { VNIR }\end{array}$} & 1 & $0.5-0.60$ & 15 \\
\hline & 2 & 0.63-0.69 & 15 \\
\hline & $3 N$ & $0.78-0.86$ & 15 \\
\hline & 3B & $0.78-0.86$ & 15 \\
\hline \multirow{6}{*}{$\begin{array}{c}\text { Aster } \\
\text { L1A } \\
\text { SWIR }\end{array}$} & 4 & $1.60-1.70$ & 30 \\
\hline & 5 & $2.145-2.185$ & 30 \\
\hline & 6 & $2.185-2.225$ & 30 \\
\hline & 7 & $2.235-2.285$ & 30 \\
\hline & 8 & $2.95-2.365$ & 30 \\
\hline & 9 & $2.360-2.430$ & 30 \\
\hline \multirow{5}{*}{$\begin{array}{c}\text { Aster } \\
\text { L1A } \\
\text { TIR }\end{array}$} & 10 & $8.125-8.475$ & 90 \\
\hline & 11 & $8.475-8.825$ & 90 \\
\hline & 12 & 8.925-9.275 & 90 \\
\hline & 13 & $10.25-10.95$ & 90 \\
\hline & 14 & $10.95-11.65$ & 90 \\
\hline
\end{tabular}

other published map and literature were used for the work.

The flow chart shown in Figure 2 illustrates the procedures followed to generate the crop moisture map.

\subsubsection{Method of LST Calculation}

Thermal atmospheric correction is must to calculate the most accurate temperature using ASTER thermal data. Here, the In-Scene Atmospheric Compensation algorithm (ISAC) [6], is applied to remove atmospheric noises from the thermal bands.

The algorithm first determines the wavelength that most often exhibits the maximum brightness temperature. This wavelength is then used as the reference wavelength. Only spectra that have their brightest temperature at this wavelength are used to calculate the atmospheric compensation. At this point, for each wavelength, the reference blackbody radiance values are plotted against the measured radiances. A line is fitted to the highest points in these plotted data and the fit is weighted to assign more weight to regions with denser sampling. The compensation for this band is then applied as the slope and offset derived from the linear regression of these data with their computed blackbody radiances at the reference wavelength. Upwelling atmospheric radiance and atmospheric transmission are approximated using the fol-

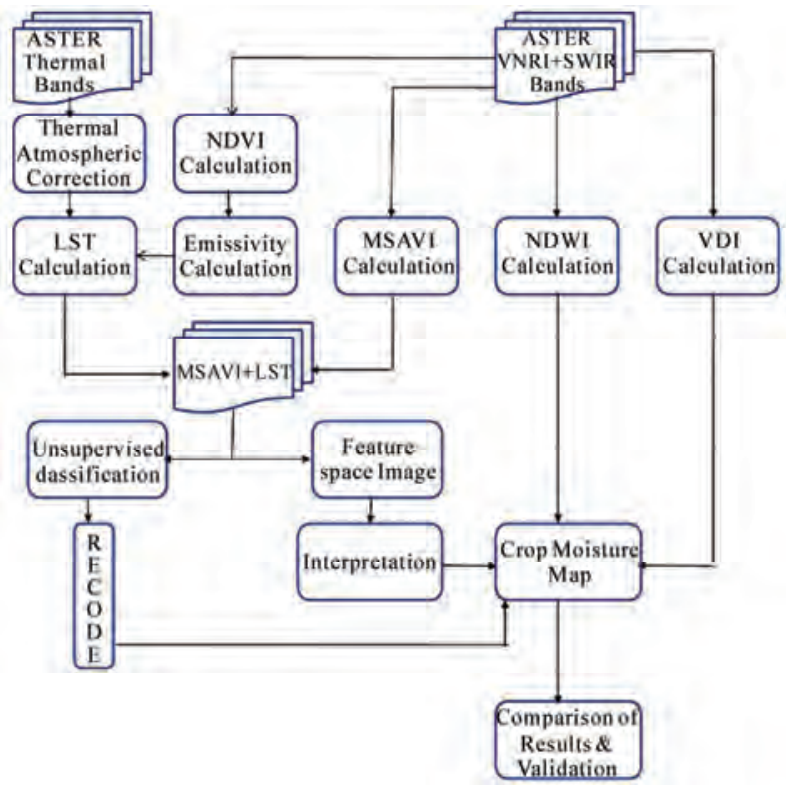

Figure 2. Processing flow for mapping vegetation moisture.

lowing method. First, the surface temperature of every pixel is estimated from the data and used to approximate the brightness temperature using the Planck function and assuming an emissivity of 1 . Next, a line is fitted (using one of two methods) to a scatter plot of radiance vs. brightness temperature. The atmospheric upwelling and transmission are then derived from the slope and offset of this line.

Satellite thermal infrared sensors measure radiances at the top of the atmosphere, from which brightness temperatures TB (also known as blackbody temperatures) can be derived by using Plank's law [7].

$$
T_{b}=\left(\frac{h c}{k \lambda}\right)\left(\frac{1}{\frac{I n\left(2 h c^{2} \lambda^{-5}\right)}{B_{\lambda}+1}}\right)
$$

where $h$ is Planck's constant $\left(6.62 \times 10^{-34} \mathrm{~J}\right.$-sec $), c$ - velocity of light $\left(2.998 \times 10^{8} \mathrm{~m} \mathrm{sec}^{-1}\right), \lambda$ - wavelength of emitted radiance $(\mathrm{m}), B_{\lambda}$ - blackbody radiance $\left(\mathrm{Wm}^{-2}\right.$ $\mu \mathrm{m}^{-1}$ ). With the known LSE, the emissivity-corrected LST (TS) can be calculated by the Stefan Boltzmann law [8].

$$
B=\varepsilon \sigma T_{s}^{4}=\sigma T_{B}^{4}
$$

Therefore,

$$
T_{S}=\frac{1}{\varepsilon^{\frac{1}{4}}} T_{B}
$$

where $\sigma$ is the Stefan Boltzmann constant $\left(5.67 \times 10^{-8}\right.$ $\left.\mathrm{Wm}^{-2} \mathrm{~K}^{-4}\right), B$ - total amount of radiation emitted $\left(\mathrm{Wm}^{2-}\right)$, 
$T_{S}$ - surface temperature $(\mathrm{K}), T_{B}$ - brightness temperature (K), $\varepsilon$ - land surface emissivity.

In order to determine an actual surface temperature it is necessary to determine the emissivity of the land surface features.

\subsubsection{NDVI Method for Emissivity Correction}

Retrieval of LST from multispectral TIR data requires an accurate measurement of emissivity values of the surface [9]. The emissivity of a surface is controlled by such factors as water content, chemical composition, structure, and roughness [10]. For vegetated surfaces, emissivity can vary significantly with plant species, areal density, and growth stage [10]. In the mean time, emissivity is a function of wavelength, commonly referred to as spectral emissivity [11]. Pixels representing the land surface are usually mixed pixels of surfaces-types such as vegetation and soil. The effective emissivity of a pixel can be estimated by summing up the contributions from its surface-types. Van de Griend and Owe (1993) [12] found a high correlation between measured emissivity and NDVI, which measured from visible and near-infrared spectral reflectance.

$$
N D V I=\frac{(I R-R)}{(I R+R)}
$$

They gave the following relation:

$$
\varepsilon=1.0094+0.047 * \ln (N D V I)
$$

But this is only valid for areas with a large patches covered by vegetation or soil. Valor and Caselles (1996) [13] proposed an operational model of determining the effective emissivity that is applicable to areas with several soil and vegetation types and changing vegetation cover:

$$
\varepsilon=\varepsilon v P v+\varepsilon s(1-P v)
$$

where $\varepsilon v, \varepsilon s$ are the emissivity of the full vegetation and bare soil, and $P_{v}$ is the vegetation cover fraction. $\varepsilon v$, $\varepsilon s$ can be obtained from the Formula (4) where the patches of vegetation and soil are selected so that they are a lot bigger than a pixel. $P_{v}$ is derived according to Carlson and Ripley (1997) [14], from:

$$
P_{v}=\left(\frac{N V D I-N V D I_{S}}{N V D I_{V}-N V D I_{S}}\right)^{2}
$$

\subsubsection{Modified Soil Adjustment Vegetation Index (MSAVI)}

A Modified Soil Adjusted Vegetation Index (MSAVI), proposed by [15] was created using ASTER VNIR image. The following equation was used to calculate the index image:

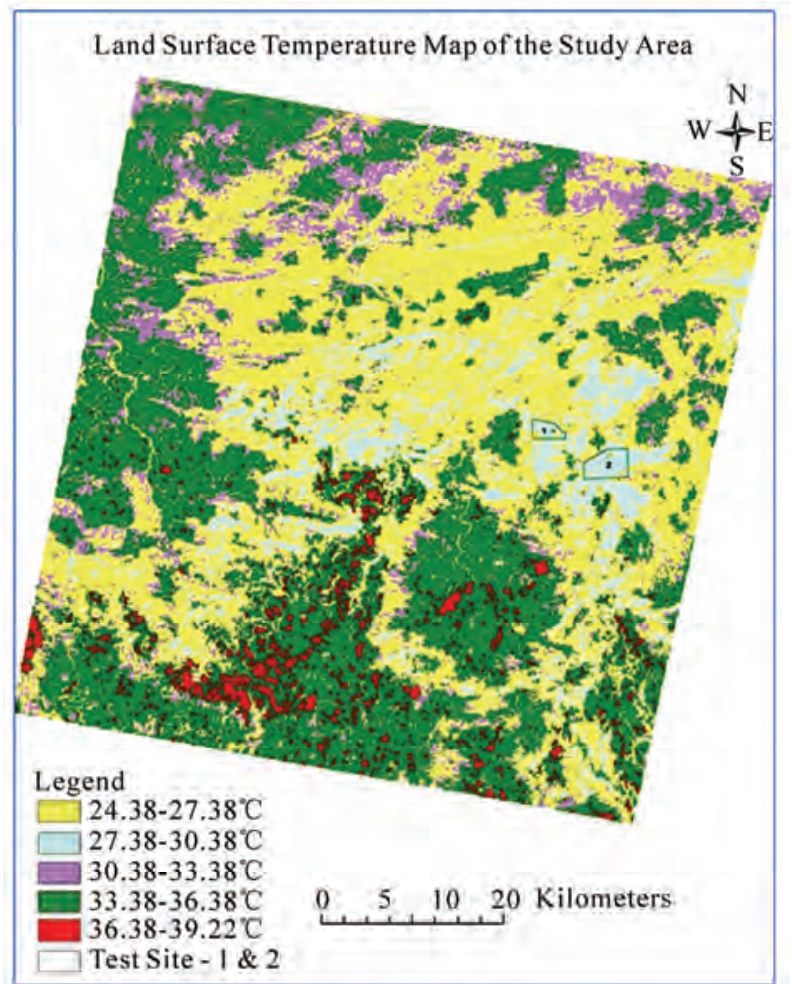

Figure 3. Distribution of land surface temperature calculated from ASTER image.

$$
\text { MSAVI }=\rho_{N}+0.5-\sqrt{\left(\rho_{N}+0.5\right)^{2}-2\left(\rho_{N}-\rho_{r}\right)}
$$

where, $\rho_{n}$ is reflectance at Near Infra Red (NIR) (ASTER Band 3n) band and $\rho_{r}$ is reflectance at Red (R) band (ASTER Band 2).

\section{Results \& Discussion}

\subsection{Estimation of Vegetation Moisture}

\subsubsection{First Approach: VI-LST Triangular Space Method}

The Vegetation Index (VI) - Land Surface Temperature (LST) Triangular Space Method proposed by Lambin and Ehrlich (1996) was used to map the relative variation of vegetation moisture within Baresanr reserved forest. The MSAVI created from ASTER VNIR image was used as Vegetation Index and Land surface kinetic temperature (in degree centigrade) calculated from ASTER TIR image was used as LST [16].

The MSAVI image and LST image were stacked to create a two layer image that was then was classified using unsupervised classification method. A feature space image was created using the two layer image. The MSAVI image layer was used along $X$ axis and the LST image layer was used along $\mathrm{Y}$ axis. The feature space 


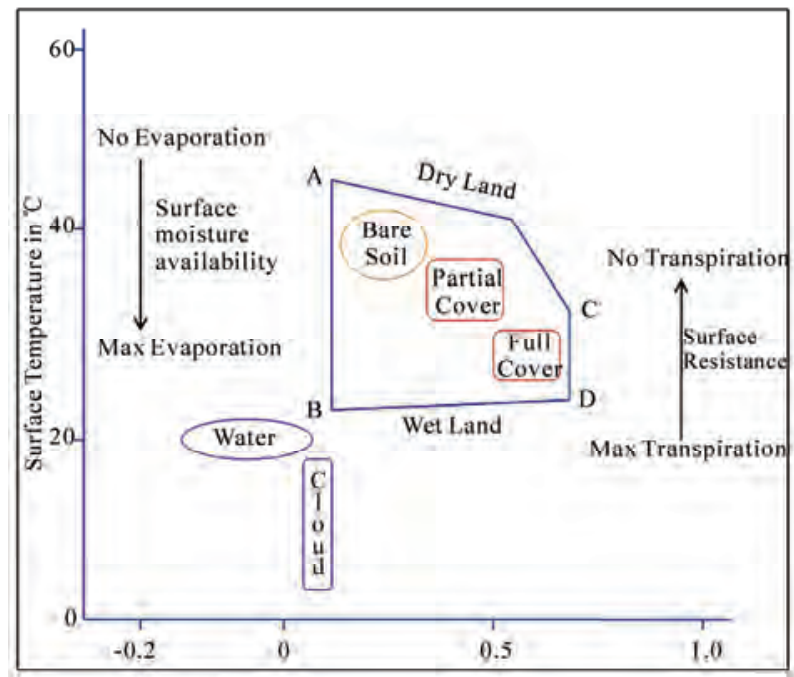

Figure 4. Feature space interpretation after Lambin and Ehrlich's (1996).

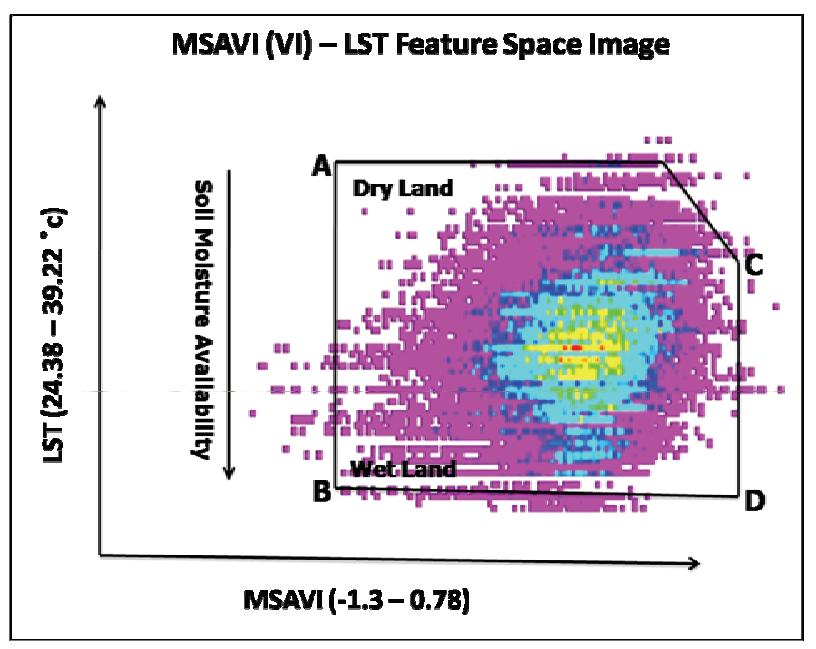

Figure 5. The feature space image created using the ASTER imagery and the comparison with Lambin and Ehrlich's (1996) interpretation. Figure 6 shows the feature identification procedure using the created feature space image.

image was used to identify the signatures of the classified image on the basis of Lambin and Ehrlich's (1996) interpretation (Figure 4).

Figure 5 shows the feature space image created using the ASTER imagery and the comparison with Lambin and Ehrlich's (1996) interpretation. Figure 6 shows the feature identification procedure using the created feature space image.

The initial classified image was recorded into three classes: Moderate Vegetation Moisture, Low Vegetation Moisture and Very Low Vegetation Moisture. Figure 7 shows the vegetation moisture classification using fea-

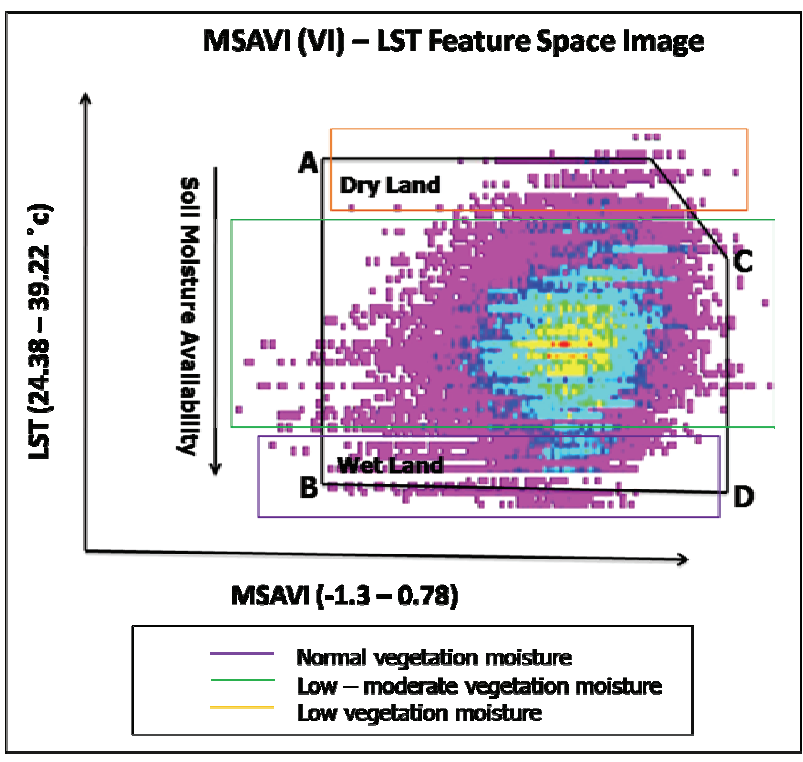

Figure 6. Procedure of moisture level identification using feature space image.

ture space image interpretation.

\subsubsection{Second Approach: NDWI Based Moisture Index}

The Normalized Differential Water Index (NDWI) proposed by $[17,18]$ was calculated using the VNIR and SWIR ASTER imagery. The equation of NDWI is as follows:

$$
N D W I=\frac{(N I R-S W I R)}{(N I R+S W I R)}
$$

The Figure 8 shows the classified vegetation moisture map.

\subsubsection{Third Approach: Vegetation Dryness Index (VDI)}

Vegetation Dryness Index (VDI) estimates vegetation water deficit at canopy level [19]. NDVI and NDWI are used to calculate the maximal and minimal water content lines. VDI is then calculated by the position of the point falling in between the maximal and minimal water content lines. VDI is a ratio between NDVI and NDWI and gives us the vegetation water stress. The Figure $\mathbf{9}$ shows the vegetation moisture variations of the test sites derived using VDI method.

$$
V D I=\frac{N V D I}{N D W I}
$$

All the classified map shows that the moisture level of the two test sites are mainly very low to low. So, the vegetations are unhealthy or stressed due to unavailability of water in this time. The percentage of the area covered by each class in the classified VDI, NDWI and MSAVI- 


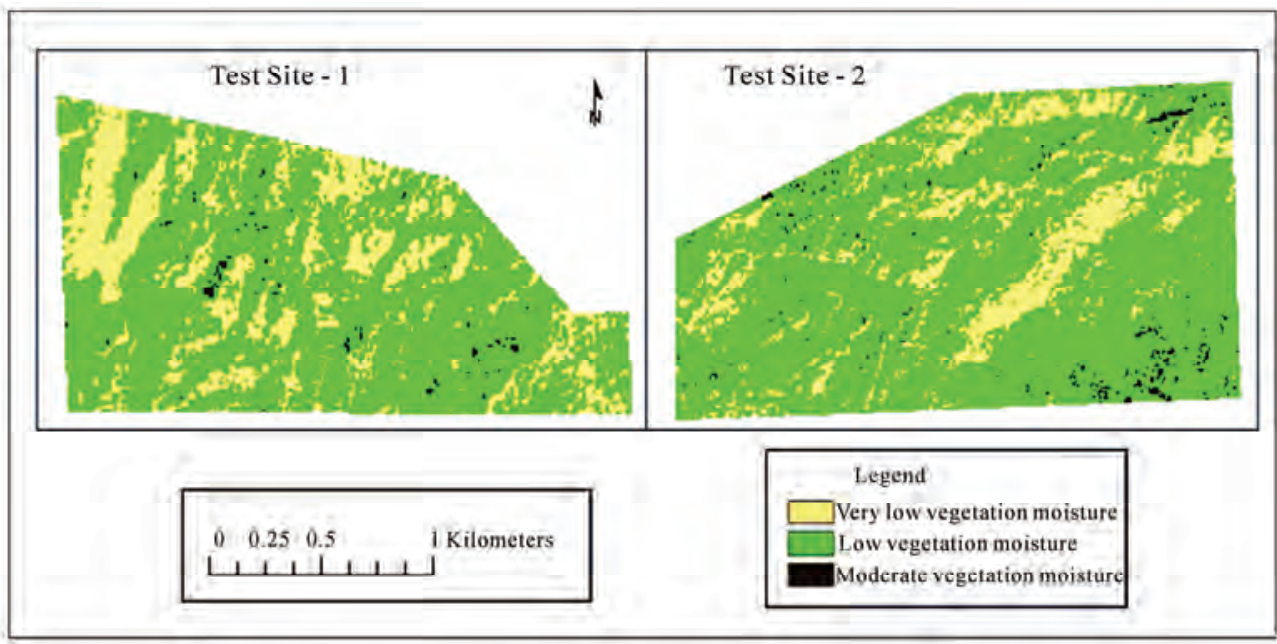

Figure 7. Vegetation moisture classification using feature space image interpretation.

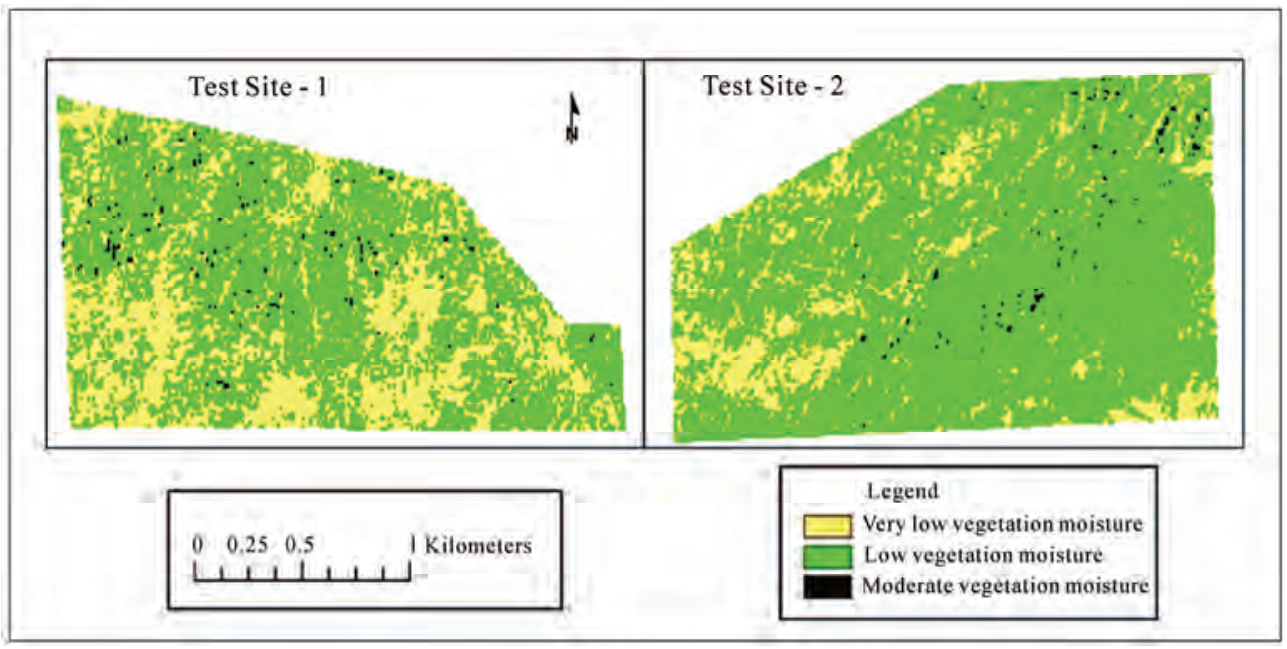

Figure 8. Classified NDWI derived vegetation moisture map.

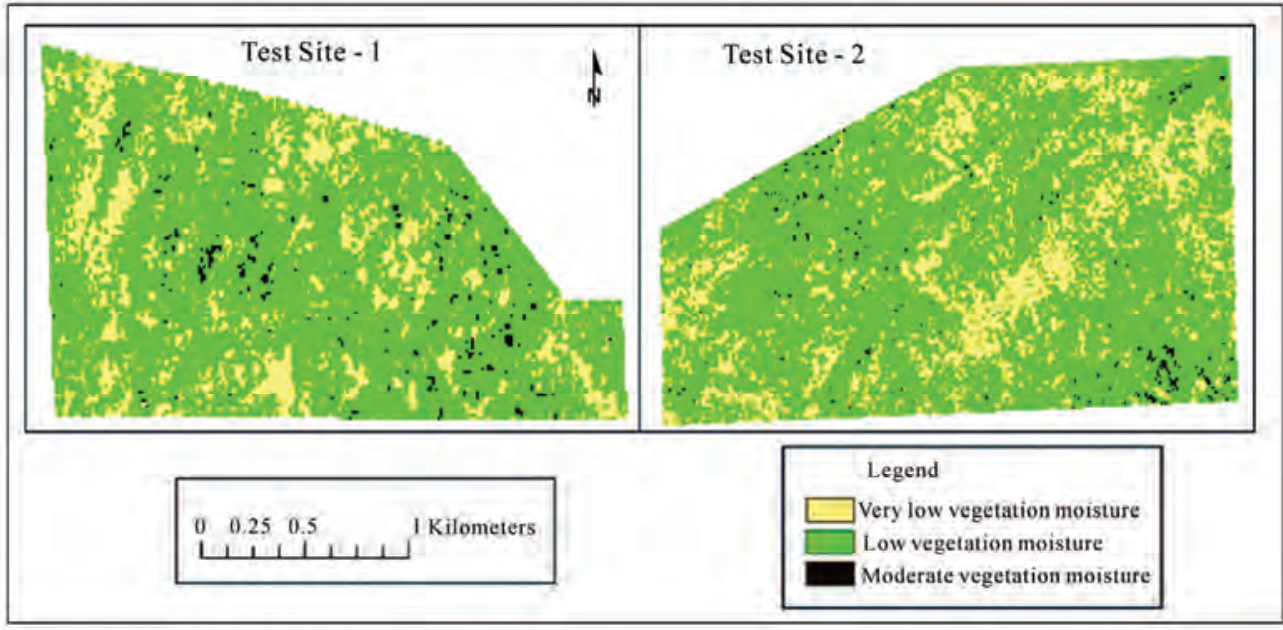

Figure 9. Classified VDI derived vegetation moisture map. 
Table 2. Variation of vegetation moisture estimated by three different methods.

\begin{tabular}{ccccccc}
\hline & \multicolumn{4}{c}{ Percentage of area coverage } \\
\cline { 2 - 7 } Moisture Level & \multicolumn{2}{c}{ VDI method } & \multicolumn{2}{c}{ NDWI method } & \multicolumn{2}{c}{$\begin{array}{c}\text { MSAVI+LST Feature space } \\
\text { interpretation method }\end{array}$} \\
\cline { 2 - 7 } & Site -1 & Site -2 & Site -1 & Site -2 & Site -1 & Site - 2 \\
\hline Moderate Vegetation Moisture & 1.05 & 0.69 & 0.61 & 1.24 & 2.20 & 1.27 \\
Low Vegetation Moisture & 78.90 & 66.42 & 68.32 & 75.21 & 71.26 & 75.18 \\
Very low Vegetation Moisture & 20.04 & 32.89 & 31.06 & 23.54 & 26.53 & 23.54 \\
\hline
\end{tabular}

LST images were calculated and tabulated to compare the values (Table 2).

\section{Conclusions}

This paper explores the relationship between LST and different vegetation index to measure the moisture content within the vegetations in drought prone area of Jharkhand state during the early summer season. The results of the analysis of the current research indicate that crop moisture can be estimated using ASTER imagery. The land surface temperature calculated from ASTER TIR image shows high temperature within the entire study area which also indicates the drought. Vegetation moisture estimated using the NDWI method does not agrees with the VDI derived vegetation moisture map but agrees with land surface temperature and precipitation map.

Vegetation moisture estimated using MSAVI-LST Triangular method does not correlate with the vegetation moisture map generated by NDWI (site-1), but does correlate with NDWI derived vegetation moisture map (site-2) and precipitation map. Therefore, it can be concluded that NDWI and MSAVI-LST Triangular method has potential to estimate vegetation moisture variation more accurately than VDI method.

Field data related to vegetation moisture may help to calibrate the method for more precise result, and suitable microwave imagery can be used to compare the results obtained from optical imagery.

\section{REFERENCES}

[1] D. A. Wilhite and M. H. Glantz, "Understanding the Drought Phenomenon: The Role of Definitions," Water International, Vol. 10, No. 3, 1985, pp. 111-120.

[2] A. F. H. Goetz, "Imaging Spectrometry for Remote Sensing Vision to Reality in 15 Years," SPIE International Society for Optical Engineers, Vol. 12, 1995, p. 2480.

[3] J. W. Rouse, R. H. Hass, J. A. Schell and D. W. Deering, "Monitoring Vegetation Systems in the Great Plains with ERTS,” Proceedings of 3rd Earth Resource Satellite-1
Symposium, NASA SP-351, Greenbelt, 1974, pp. 310$-317$.

[4] E. F. Lambin and D. Ehrlich, "The Surface Temperature-Vegetation Index Space for Land Cover and LandCover Change Analysis," International Journal of Remote Sensing, Vol. 17, No. 17, 1996, pp. 1087-1105.

[5] ASTER Reference Guide Version, "Earth Remote Sensing Data Analysis Centre 1.0,” March 2003.

[6] ITT Visual Information Solutions, "ENVI User's Guide," Version 4.5, 2008.

[7] B. L. Markham and J. L. Barkewr, "Landsat MSS and TM Post Calibration Dynamic Ranges, Exoatmospheric Reflectance and At-Satellite Temperatures,” EOSAT Landsat Technical Notes 1, 1986, pp. 3-8.

[8] R. P. Gupta, “Remote Sensing Geology,” Springer-Verlag Berlin Heidelberg, Germany, 1991.

[9] V. Caselles, C. Coll, E. Valor and E. Rubio, "Mapping Land Surface Emissivity Using AVHRR Data: Application to La Mancha, Spain,” Remote Sensing Review, Vol. 12, No. 3-4, 1995, pp. 311-333.

[10] W. C. Snyder, Z. Wan, Y. Zhang and Y. Z. Feng, "ClasSification-Based Emissivity for Land Surface Temperature Measurement from Space," International Journal of Remote Sensing, Vol. 19, No. 14, 1998, pp. 2753-2774.

[11] P. Dash, F. M. Gottsche, F. S. Olesen and H. Fischer, "Land Surface Temperature and Emissivity Estimation from Passive Sensor Data: Theory and Practice Current Trends," International Journal of Remote Sensing, Vol. 23, No. 13, 2002, pp. 2563-2594.

[12] van de Griend, A. A. and M. Owe, “On the Relationship Between Thermal Emissivity and the Normalized Difference Vegetation Index for Natural Surfaces,” International Journal of Remote Sensing, Vol. 14, No. 6, 1993, pp. 1119-1131.

[13] E. Valor and V. Caselles, "Mapping Land Surface Emissivity from NDVI: Application to European, African, and South American Areas," Remote Sensing of Environment, Vol. 57, No. 3, 1996, pp. 167-184.

[14] T. N. Carlson and D. A. Ripley, "On the Relation Between NDVI, Fractional Vegetation Cover and Leaf Area Index," Remote Sensing of Environment, Vol. 62, No. 3, 1997, pp. 241-252. 
[15] J. Qi, A. Chehbouni, A. R. Huete, Y. Kerr and S. Sorooshian, "A Modified Soil Adjusted Vegetation Index (MSAVI),” Remote Sensing of Environment, Vol. 48, 1994, pp. 119-126.

[16] A. K. M. Hossain, G. Easson and V. K. Boken, "Mapping Spatial Variation in Surface Moisture Using Reflective and Thermal ASTER Imagery for Southern Africa," ASPRS 2006 Annual Conference, Reno, 1-5 May 2006.

[17] G. Tian, L. B. Jupp, F. Qiang, W. Bingfang and H. Qin, "Drought Monitoring of Crop Using Remote Sensing and
GIS,” Journal of Remote Sensing, Vol. 6, No. (Suppl.), 2002, pp. 145-152.

[18] B. C. Gao, “NDWI - A Normalized Difference Water Index for Remote Sensing of Vegetation Liquid Water from Space,” Remote Sensing of Environment, Vol. 58, No. 3, 1996, pp. 257-266.

[19] M. Maki, M. Ishiahra and M. Tamura, "Estimation of Leaf Water Status to Monitor the Risk of Forest Fires by Using Remotely Sensed Data," Remote Sensing of Environment, Vol. 90, No. 3, 2004, pp. 441-450. 